\title{
Smoking Modulation of $\mu$-Opioid and Dopamine D2 Receptor-Mediated Neurotransmission in Humans
}

\author{
David J Scott', Edward F Domino², Mary M Heitzeg', Robert A Koeppe ${ }^{3}$, Lisong $\mathrm{Ni}^{2}$, Sally Guthrie ${ }^{4}$ and \\ Jon-Kar Zubieta*, I,3 \\ 'Department of Psychiatry, Molecular and Behavioral Neuroscience Institute, University of Michigan, Ann Arbor, MI, USA; ${ }^{2}$ Department of \\ Pharmacology, University of Michigan, Ann Arbor, MI, USA; ${ }^{3}$ Department of Radiology, University of Michigan, Ann Arbor, MI, USA; \\ ${ }^{4}$ Department of Clinical Pharmacy, College of Pharmacy, University of Michigan, Ann Arbor, MI, USA
}

\begin{abstract}
This is a pilot examination of the hypothesis that some of the effects of smoking cigarettes in humans are mediated through nicotine activation of opioid and dopamine (DA) neurotransmission. Neuroimaging was performed using positron emission tomography and the radiotracers [ $\left.{ }^{\prime \prime} \mathrm{C}\right]$ carfentanil and [ ' $\mathrm{C}$ ]raclopride, labeling $\mu$-opioid and DA D2 receptors, respectively. Six healthy male smokers were abstinent overnight. After radiotracer administration, subjects smoked two denicotinized cigarettes, followed 45 min later by two average nicotine cigarettes. Dynamic data were acquired over $90 \mathrm{~min}$, and transformed into parametric maps of receptor availability in vivo (binding potential, BP), corresponding to low and high nicotine smoking periods and analyzed on a voxel-by-voxel basis using SPM'99 and correction for multiple comparisons. Significant activation of $\mu$-opioid receptor-mediated neurotransmission from denicotinized to average nicotine conditions was observed in the right anterior cingulate cortex. DA D2 neurotransmission was activated in the ventral basal ganglia, correlating with Fagerström scale nicotine dependence scores. Lower $\mu$-opioid receptor BP was also detected during the denicotinized smoking condition in the smoker group, compared to baseline scans in non-smokers, in the cingulate cortex, thalamus, ventral basal ganglia, and amygdala. These reductions were reversed during the average nicotine condition in the thalamus, ventral basal ganglia and amygdala. These data point to both the feasibility of simultaneously examining opioid and DA neurotransmission responses to smoking in humans, as well as to the need to examine non-nicotine aspects of smoking to more fully understand the behavioral effects of this drug.

Neuropsychopharmacology (2007) 32, 450-457. doi:I0. I 038/sj.npp. I 30 I238; published online 8 November 2006
\end{abstract}

Keywords: nicotine; $\mu$-opioid receptors; positron emission tomography; dopamine; opioids; craving

\section{INTRODUCTION}

Twenty-six years have elapsed since Karras and Kane (1980) reported that tobacco smoking and craving for tobacco smoke by humans were reduced by the nonselective opioid receptor antagonist naloxone. Subsequent human clinical trials with naloxone or the longer acting opioid receptor antagonist naltrexone showed inconsistent results both in the degree that these agents diminished tobacco smoking as well as on their behavioral effects (Nemeth-Coslett and Griffiths, 1986; Gorelick et al, 1988; Sutherland et al, 1995; Wewers et al, 1999). Aceto et al (1993) examining the analgesic effects of nicotine in rodents, and Pomerleau (1998) in a review of both human and animal data, postulated that

*Correspondence: Dr J-K Zubieta, Department of Psychiatry, Molecular and Behavioral Neuroscience Institute, University of Michigan, 205 Zina Pitcher Place, Ann Arbor, MI 48 I09-0720, USA, Tel: +I 734 763 6843, Fax: + 734647 4I30, E-mail: zubieta@umich.edu

Received 9 January 2006; revised 19 June 2006; accepted 24 June 2006 Online publication: 21 September 2006 at http://www.acnp.org/ citations/Npp092 1060600 I0/default.pdf nicotine produced both pro- and antiopioidergic effects. These were further confounded by the complexity of this neurotransmitter system and its possible involvement in both reinforcing and withdrawal phenomena.

In animal models, evidence of nicotine-induced alterations in opioid peptide protein and mRNA content (Houdi et al, 1991; Di Chiara, 2000), and endogenous opioid release (Davenport et al, 1990) have been described in the central nervous system, as well as in peripheral preparations (Eiden et al, 1984). Although nicotine self-administration has not consistently been found to be altered by naloxone, naloxone has been shown to precipitate a withdrawal syndrome in rats treated chronically with nicotine (Malin et al, 1993; Carboni et al, 2000b). Nicotine also induced dopamine (DA) release in the rat nucleus accumbens and nucleus of the stria terminalis. These effects were abolished by the administration of long-acting opioid antagonists or mixed agonists-antagonists (Tanda and Di Chiara, 1998; Carboni et al, 2000a), but not by the shorter acting antagonist naloxone (Carboni et al, 2000b). However, the latter group confirmed the precipitation of a physical withdrawal 
syndrome by naloxone in rats chronically treated with nicotine, and suggested the presence of dissociable dopaminergic and opioid components in the effects of this substance.

It is increasingly recognized that dopaminergic and opioid mechanisms form part of neuronal systems involved in reward-reinforcement (Zubieta et al, 1996; Koob and Le Moal, 2001; Volkow et al, 2004; Zald et al, 2004) as well as responses to stress and salient stimuli (Pruessner et al, 2004; Zubieta et al, 2003), all of which have been involved in the use of and dependence on nicotine and tobacco smoking.

Neuroimaging techniques targeting specific molecular markers with radiolabeled tracers allow the noninvasive examination of drug effects in humans. In some cases, these radiotracers are sensitive to changes in synaptic concentration of endogenous neurotransmitters (eg DA release using $\left[{ }^{11} \mathrm{C}\right]$ raclopride, endogenous opioid release with $\left[{ }^{11} \mathrm{C}\right] \mathrm{car}-$ fentanil) (Laruelle, 2000; Zubieta et al, 2001). Using these techniques, evidence of nicotine-induced DA release has been described by Brody et al (2002) by scanning volunteers with $\left[{ }^{11} \mathrm{C}\right]$ raclopride before and after cigarette smoking outside the scanner.

In the present pilot study, we examined the feasibility of detecting changes in DA D2 and $\mu$-opioid receptormediated neurotransmission from conditions of smoking low (denicotinized) to average nicotine content cigarettes during positron emission tomography (PET) scanning. Under the experimental conditions utilized, the activation of this neurotransmitter system is observed as reductions in the in vivo availability (binding potential, BP) of $\mu$-opioid or DA D2 receptors, as measured with PET and the radiotracers $\left[{ }^{11} \mathrm{C}\right]$ carfentanil and $\left[{ }^{11} \mathrm{C}\right]$ raclopride. The design utilized here differs in several aspects from that employed by Brody et al (2002). Subjects were scanned during the act of smoking after overnight withdrawal and using standardized nicotine content cigarettes. Furthermore, we utilized low nicotine content cigarettes as the control condition to account for non-nicotine-related effects of smoking. In Brody et al (2002), subjects were allowed to smoke before the scanning period, removed from the scanner after a baseline scan, half of them were allowed to smoke their favorite brand of cigarettes, and then rescanned. The present design permits the direct ascertainment of the acute effects of cigarette smoking and to relate them to concurrent plasma levels of nicotine.

\section{MATERIALS AND METHODS}

\section{Subjects}

Six healthy right-handed male volunteers, between 21 and 33 years of age (mean \pm SD $25 \pm 4.5$ ) who smoked 15-20 $(16.7 \pm 2.6)$ cigarettes per day were recruited by advertisement. A group of six age- and sex-matched nonsmoking volunteers were also recruited for comparison of baseline receptor binding measures. Subjects underwent physical and neuropsychiatric examinations and reviews of their medical history. Undiagnosed current or past psychiatric conditions were ruled out using the Structured Interview for DSM-IV, nonpatient version (SCID-IV NP; First et al, 1995). Only subjects with no current or past history of serious or acute physical illnesses, including pain, neurologic or psychiatric illness, substance dependence (except tobacco smoking) or recent substance abuse (less than 1 year), and who had not taken psychoactive substances within the prior month were included. All subjects were medication free. Subjects who met the above criteria completed the Fagerström test (Heatherton et al, 1991) to provide an assessment of the degree of tobacco dependence. After the study was completely described to the subjects, written informed consent was obtained. The study was reviewed and approved by the Institutional Review Board for Human Subject Research and the Radioactive Drug Research Committee at the University of Michigan.

Subjects reported to the PET suite of the Nuclear Medicine Division at University Hospital at 0730 hours on the day of the study. Smokers had been instructed to cease cigarette or tobacco use overnight, approximately $12 \mathrm{~h}$ before the study. Their compliance was confirmed with breath carbon monoxide (CO) testing. A sample of expired air was analyzed for $\mathrm{CO}$ in parts per million (p.p.m.) using a $\mathrm{CO}$ detector (Vitalograph Breath CO Model BC1349, Vitalograph Inc., Lenexa, KS). Expired air CO levels greater than 10 p.p.m. required an extensive reinterview to determine possible noncompliance with the no smoking request within the past $12 \mathrm{~h}$. This cutoff level was based on previous work showing mean exhaled CO levels in female and male overnight abstinent smokers of $8.1 \pm 6.7$ and 7.2 \pm 4.2 p.p.m., respectively (Domino and Ni, 2002). All subjects appeared compliant with this requirement. Nonsmokers were studied only under baseline conditions, without intervention.

\section{Design}

During $90 \mathrm{~min}$ PET scans with $\left[{ }^{11} \mathrm{C}\right]$ carfentanil and $\left.{ }^{11} \mathrm{C}\right]$ raclopride, subjects smoked two pairs of cigarettes for $5 \mathrm{~min}$ each, in a dimly lit room. All subjects received both radiotracers, in randomized and counterbalanced order (half of the subjects received $\left[{ }^{11} \mathrm{C}\right]$ carfentanil first, followed by $\left[{ }^{11} \mathrm{C}\right]$ raclopride). Subjects first smoked a denicotinized cigarette at 2 and 12 min after the beginning of the scanning period. Subjects then smoked an average content cigarette at 40 and $50 \mathrm{~min}$ into the scan. In this manner, the entire scan could be separated into two phases: an early, denicotinized phase, followed by a later, average nicotine phase. The two different types of research cigarettes were obtained through the courtesy of Dr Frank P Gullota (retired) and Ms Cynthia S Hayes of the Philip Morris Research Center, Richmond, VA. The nicotinecontaining cigarette was prepared with unextracted tobacco (nicotine $1.01 \mathrm{mg} /$ cigarette and tar $9.5 \mathrm{mg} /$ cigarette). The denicotinized cigarette was made with almost $100 \%$ extracted tobacco (nicotine $0.08 \mathrm{mg} /$ cigarette and tar $9.1 \mathrm{mg} /$ cigarette). Both cigarettes contained identical filter tips and were made from the same blend of tobacco with no flavors added. Thus, their tar content was almost identical (9.5 vs $9.1 \mathrm{mg}$ ) and only the $\mathrm{mg}$ of nicotine per cigarette was markedly different ( 1.01 vs $0.08 \mathrm{mg}$ ). Subjects were encouraged to puff every $30 \mathrm{~s}$ for a total number of 10 puffs per cigarette. Volume of each puff was not controlled for, and subjects were instructed to smoke as they would normally do. The order of the scans was not randomized to avoid carryover effects of the nicotine-containing cigarettes. 


\section{Subjective Ratings}

Subjects were administered visual analog scales (VAS) three times throughout the session. The VAS were administered before the subject's entry into the PET scanner (baseline), at $40 \mathrm{~min}$ after scan initiation (rating the denicotinized condition), and immediately after the end of the scanning period (rating the average cigarette condition). On the VAS, subjects were asked to rate, on a scale of 0 (not at all) to 10 (most ever) how they felt at the time with regard to: 'craving for a cigarette', 'relaxed', 'nervous', and 'alert'.

\section{Neuroimaging Methods}

PET scans were acquired with a Siemens $\mathrm{HR}^{+}$scanner in three-dimensional (3-D) mode (reconstructed FWHM resolution $\sim 5.5 \mathrm{~mm}$ in-plane and $5.0 \mathrm{~mm}$ axially), with septa retracted and scatter correction. Participants were positioned in the PET scanner gantry, and two intravenous (antecubital) lines were placed. A light forehead restraint was used to eliminate intrascan head movement. $\left[{ }^{11} \mathrm{C}\right] \mathrm{car}-$ fentanil was synthesized at high specific activity $(>2000 \mathrm{Ci} /$ mmol) by the reaction of $\left[{ }^{11} \mathrm{C}\right]$ methyliodide and a nonmethyl precursor as described previously (Jewett, 2001). $\left[{ }^{11} \mathrm{C}\right]$ raclopride was synthesized at high specific activity $(>2000 \mathrm{Ci} / \mathrm{mmol}$ ) by the reaction of O-desmethyl raclopride with ${ }^{11} \mathrm{C}$-methyl triflate. In each of the two scans, $10-15 \mathrm{mCi}$ was administered, with a mass of carfentanil injected of $0.048 \pm 0.037 \mu \mathrm{g} / \mathrm{kg}$ per scan and a total mass of raclopride of $0.089 \pm 0.047 \mu \mathrm{g} / \mathrm{kg}$ per scan. This ensured that the compounds were administered in tracer quantities, that is, subpharmacological doses occupying less than $1 \%$ of the available receptors. Fifty percent of the radiotracer doses were administered as a bolus, and the remaining $50 \%$ by continuous infusion for the remainder of the study.

Images were reconstructed using iterative algorithms (brain mode; FORE/OSEM four iterations, 16 subsets; no smoothing) into a $128 \times 128$ pixel matrix in a $28.8 \mathrm{~cm}$ diameter field of view. Attenuation correction was performed through a 6-min transmission scan $\left({ }^{68} \mathrm{Ge}\right.$ source) obtained before the PET study, also with iterative reconstruction of the blank/transmission data followed by segmentation of the attenuation image. Small head motions during emission scans were corrected by an automated computer algorithm for each subject before analysis, and the images coregistered to each other with the same software (Minoshima et al, 1993). Time points were then decay-corrected during reconstruction of the PET data.

Image data were then transformed on a voxel-by-voxel basis into two sets of parametric maps: (a) a tracer transport measure $\left(K_{1}\right.$ ratio), and (b) a receptor-related measure (distribution volume ratio, DVR). To avoid the need for arterial blood sampling, these measures were calculated using a modified Logan graphical analysis (Logan et al, 1996) using the occipital cortex (an area devoid of $\mu$-opioid receptors) or the cerebellum (devoid of DA D2 receptors) as the reference regions. With the partial bolus, continuous infusion radiotracer administration protocol used, the Logan plot becomes linear by 5-7 min after the start of radiotracer administration, allowing the calculation of receptor measures early after each tracer administration. The slope of the Logan plot is equal to the $\left(B_{\max } / K_{\mathrm{d}}\right)+1$ for this receptor site (receptor concentration divided by its affinity for the radiotracer) and it has been referred to as the DVR. $B_{\max } / K_{\mathrm{d}}$ (or DVR -1 ) is the 'receptor related' measure (BP, or receptor availability in vivo; $B_{\max }=$ concentration of receptors, $K_{\mathrm{d}}=$ receptor affinity for the radiotracer). As changes in $B_{\max } / K_{\mathrm{d}}$ will cause a change in the slope of the Logan plot, we measured DVR during both the early and late phases of each scan. The slope during the early phase was estimated from 5 to $40 \mathrm{~min}$ postinjection, whereas the slope for the second phase was estimated from 45 to $90 \mathrm{~min}$ postinjection.

Anatomical MRI scans were acquired before PET scanning on a 1.5 Tesla scanner (Sigma, General Electric, Milwaukee, WI). Acquisition sequences were axial SPGR IR-Prep MR $\left(\mathrm{TE}=5.5, \mathrm{TR}=14, \mathrm{TI}=300\right.$, flip angle $=20^{\circ}$, $\mathrm{NEX}=1,124$ contiguous images, $1.5 \mathrm{~mm}$ thickness), followed by axial $\mathrm{T} 2$ and proton density images $(\mathrm{TE}=20$ and 100 , respectively; $\mathrm{TR}=4000, \mathrm{NEX}=1,62$ contiguous images, $3 \mathrm{~mm}$ thickness). $K_{1}$ and DVR images for each experimental period and MR images were coregistered to each other and to the International Consortium for Brain Mapping (ICBM) stereotactic atlas orientation. Statistical parametric maps of differences between conditions (denicotinized $v s$ average nicotine) were generated by anatomically standardizing the T1-SPGR MRI of each subject to the ICBM stereotactic atlas coordinates, with subsequent application of this transformation to the DA D2 and $\mu$-opioid receptor binding maps. The accuracy of coregistration and nonlinear warping algorithms was confirmed for each subject individually by comparing the transformed MRI and PET images to each other and the ICBM atlas template.

\section{Image Data Analysis}

Differences within subjects, between conditions (effects of nicotine) and between subject groups (differences in baseline binding measures between controls and smokers) were mapped into stereotactic space using $z$ maps of statistical significance with SPM'99 and Matlab software, with a general linear model and correction for multiple comparisons. No global normalization was applied to the data, and therefore the calculations presented are based on absolute $B_{\max } / K_{\mathrm{d}}$ estimates. Only regions with specific $\mu$-opioid and DA D2 receptor binding were included in the analyses (voxels with DVR values $>1.2$ times the mean global image value as calculated with SPM'99). To compensate for small residual anatomic variations across subjects and to improve signal to noise ratios, a 3-D Gaussian filter (FWHM $6 \mathrm{~mm}$ ) was applied to each scan. For each subtraction analysis, one-sample or two-sample, twotailed $t$-statistic values were calculated for each pixel using a smoothed pooled variance across pixels. Significant differences and correlations were detected using a statistical threshold that controls a Type-I error rate at $p=0.05$ for multiple comparisons, estimated using the Euler characteristic and the number of pixels in the gray matter and image smoothness (Worsley et al, 1992). Z scores were also deemed significant if they reached statistical thresholds after correction for the size of the cluster under consideration (Friston et al, 1994). Correlation coefficients described in the text were calculated by extracting from the image data 
the values of voxels contained in an area where significant differences were obtained in the voxel-by-voxel analysis, down to a threshold of $p=0.01$. Correlations between activation of neurotransmission and the changes in psychophysical measures and nicotine and cotinine plasma levels were further calculated with two-tailed Pearson's correlations at $p<0.05$.

\section{RESULTS}

Subject characteristics, rating scales, and venous plasma levels of nicotine during the denicotinized and average nicotine cigarette administrations are shown in Table 1. The average Fagerström score for smoker participants was $5.0 \pm 2.0$. The time-course of the VAS scores collected shows

Table I Subject Characteristics and Plasma Levels of Nicotine

\begin{tabular}{lc}
\hline Age (years) & $25 \pm 4.5$ \\
Cigarettes/day & $16.7 \pm 2.6$ \\
Fagerström scale & $5 \pm 2$ \\
Denicotinized condition venous nicotine (CFN) & $4.2 \pm 0.7$ \\
Denicotinized condition venous nicotine (RAC) & $5.0 \pm 0.2$ \\
Average nicotine condition venous nicotine (CFN) & $17.8 \pm 3.7$ \\
Average nicotine condition venous nicotine (RAC) & $12.2 \pm 1.8$ \\
\hline
\end{tabular}

Data show the mean \pm I SD of subject characteristics and venous plasma levels of nicotine during denicotinized and average nicotine content cigarette smoking during $\left[{ }^{\prime \prime} \mathrm{C}\right]$ carfentanil (CFN) and $\left[{ }^{\prime \prime} \mathrm{C}\right]$ raclopride (RAC) scanning in $\mathrm{ng} / \mathrm{ml}$. high variability between individuals, and no significant differences between conditions were obtained in this small sample (paired, two-tailed $t$-tests, $p>0.05$ ). Mean ratings for 'craving' and 'nervous' were lower after both the denicotinized and average nicotine cigarettes, whereas 'alert' and 'relaxed' tended to increase after smoking in both conditions (alert: baseline $4.0 \pm 2.1$, denicotinized $5.0 \pm 2.8$, nicotine $5.5 \pm 2.6$; relaxed: baseline $4.3 \pm 2.2$, denicotinized $5.7 \pm 2.9$, nicotine $6.2 \pm 2.5$; craving: baseline $4.8 \pm 1.9$, denicotinized $5.0 \pm 2.8$, nicotine $5.5 \pm 2.6$; nervous: baseline $3.5 \pm 2.6$, denicotinized $2.2 \pm 1.5$, nicotine $2.2 \pm 2.4$ ).

\section{Baseline Receptor Binding in Smokers and Nonsmokers}

Smokers exhibited significantly lower baseline $\mu$-opioid receptor BP during the denicotinized cigarette condition compared to the nonsmoker sample during no-intervention scans (Figure 1). Significantly lower BP was observed in the rostral anterior cingulate, thalamus, nucleus accumbens, and amygdala with reductions in BP in the smoker group ranging from $13 \%$ in the rostral cingulate to $42 \%$ in the thalamus. No significant differences were obtained between smokers and nonsmokers for baseline DA D2 receptor BP.

\section{$\mu$-Opioid System Activation during Smoking}

Evidence of activation of $\mu$-opioid receptor-mediated neurotransmission (reductions in the in vivo BP measure from low to high nicotine conditions) was obtained in the right anterior cingulate, including rostral, pregenual

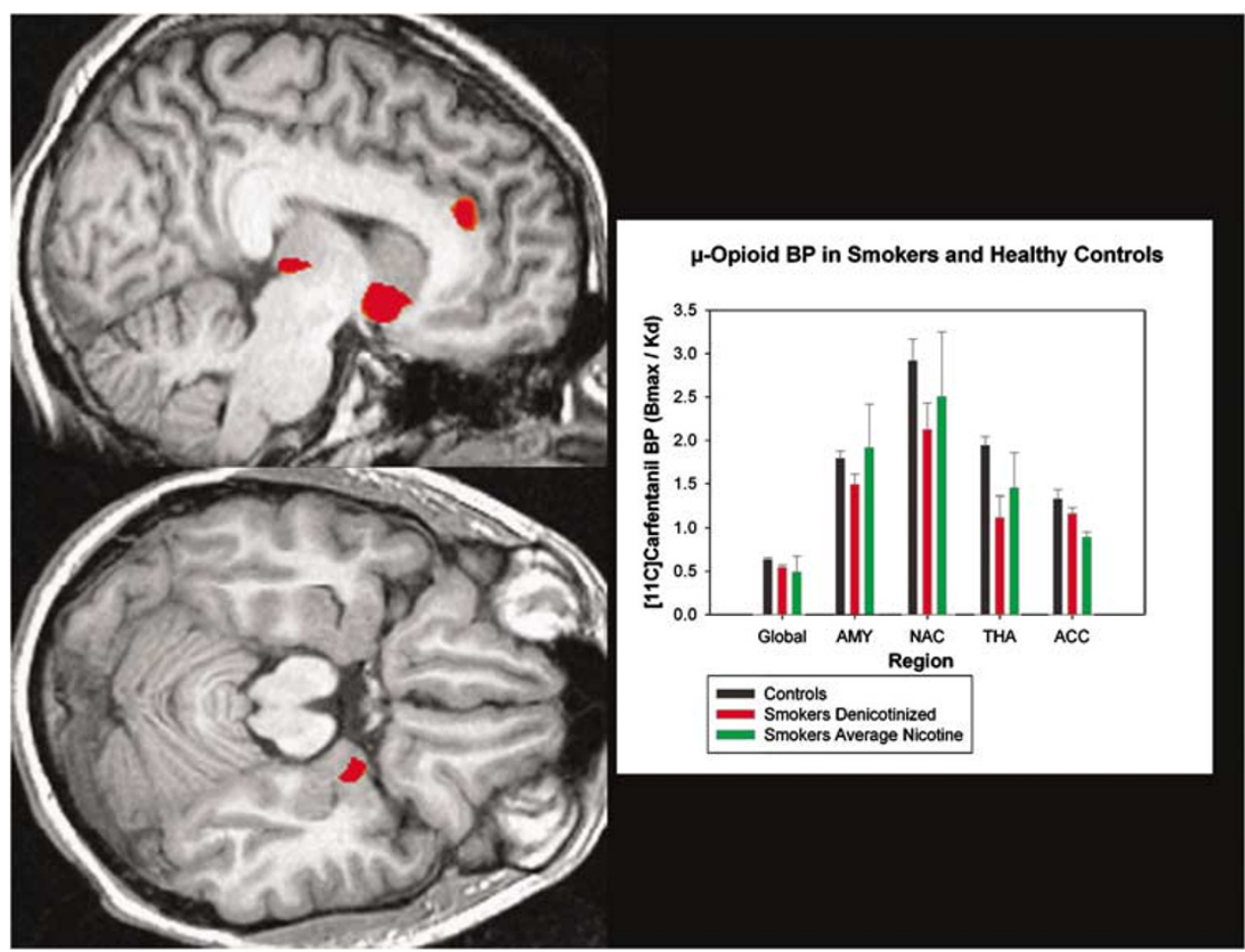

Figure I $\mu$-Opioid receptor BP in healthy controls at baseline and smokers during the smoking of denicotinized and average nicotine content cigarettes. Bar graph showing the mean \pm I SEM of $\mu$-opioid receptor BP values as measured with $\left[{ }^{\prime \prime} \mathrm{C}\right]$ carfentanil for whole brain (Global), amygdala (AMY), nucleus accumbens (NAC), thalamus (THA), and rostral anterior cingulate (ACC) in nonsmokers at baseline, and in smokers during smoking denicotinized and average nicotine content cigarettes. 

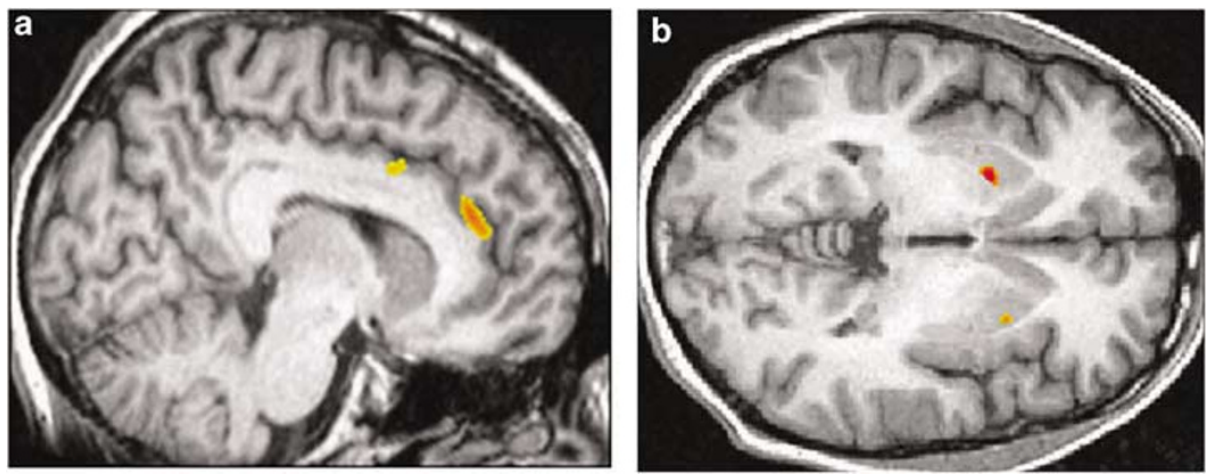

Figure 2 Areas showing significant activation of $\mu$-opioid (a) and DA D2 (b) neurotransmission from denicotinized to average nicotine content smoking conditions. Areas where statistically significant reductions in $\mu$-opioid (a) and DA D2 (b) receptor BP were detected from denicotinized to average nicotine content smoking conditions are shown in color superimposed over an anatomically standardized magnetic resonance image in saggital and axial views. Image data are displayed according to standard radiological convention so that the left side of the image corresponds to the right side of the brain.

$\left(x, y, z\right.$ coordinates, in $\mathrm{mm}, 1,38,1$; cluster size $=140 \mathrm{~mm}^{3}$; $z=4.18, p<0.05$ after correction for multiple comparisons), and dorsal peaks $\left(x, y, z, 5,10,42\right.$; cluster size $=360 \mathrm{~mm}^{3}$; $z=4.23, p<0.001$ ) (Figure 2 ). The average $\%$ reduction in the BP measure was 20.7 and $24.2 \%$ for the above regions.

In addition of these effects, we tested whether effects in the opposite direction (increases in the BP measure after smoking, presumably reflecting reductions in endogenous opioid tone) could also be detected. Significant increases in $\mu$-opioid receptor BP from denicotinized to average nicotine conditions were also observed, localized in the left amygdala $\left(x, y, z,-25,-3,-18\right.$; cluster size $=695 \mathrm{~mm}^{3} ; z=7.65$, $p<0.0001$ ) and left ventral basal ganglia (localized in the nucleus accumbens, and extending laterally and posterior into the ventral pallidum $(x, y, z,-13,13,5$; cluster size $\left.=664 \mathrm{~mm}^{3} ; z=5.58, p<0.0001\right)$, as well as in the right thalamus $\left(x, y, z, 19,-4,-17\right.$; cluster size $=521 \mathrm{~mm}^{3}$; $z=5.89, p<0.0001)$. These effects corresponded to $\%$ increases in BP that ranged from $28.4 \%$ in the amygdala to $33.0 \%$ in the ventral basal ganglia.

To ensure that the differences between early (denicotinized) and late (average nicotine content) nicotine conditions and experimental periods were not due to systematic differences between data from early and late scans (possibly owing to order effects, differences in statistical noise, or Logan plot biases), we examined BP data for the regions found significant in the above analyses in the six healthy controls without intervention. No significant differences between early and late scanning periods were obtained for these analyses (average \% change mean $\pm \mathrm{SD}$ ): rostral anterior cingulate $-1 \pm 9 \%$, dorsal anterior cingulate $4 \pm 6 \%$, thalamus $1 \pm 17 \%$, ventral pallidum $1 \pm 8 \%$, amygdala $16 \pm 28 \%$ (paired, two-tailed $t$-tests, $p>0.05$ ). Similarly, no significant clusters were detected in voxel-by-voxel analyses with SPM'99 when early and late phases of the scans were examined in the nonsmoker group without intervention, down to a threshold of $p<0.01$ without correction for multiple comparisons.

\section{DA D2 System Activation during Smoking}

Reductions in DA D2 BP, reflecting activation of DA neurotransmission, were observed in the left ventral basal ganglia $\left(x, y, z,-23,6,-2\right.$; cluster size $=966 \mathrm{~mm}^{3}$; $z=6.51, p<0.0001$ after correction for multiple comparisons). The percent change in $\mathrm{BP}$ from denicotinized to average nicotine smoking in this region was $9.98 \%$. In contrast to the effects in the opioid system, no significant increases in DA D2 BP (deactivation of DA D2 neurotransmission) were observed.

Correlations between behavioral effects of smoking and changes in receptor $B P$. Increases in thalamic $\mu$-opioid receptor BP from denicotinized to nicotine smoking conditions were significantly correlated with the change in the 'alert' score $(r=0.86, p<0.03)$, but not other VAS scores or Fagerström ratings. For the DA D2 system, nicotineinduced changes in ventral basal ganglia BP did not show significant correlations with VAS scores. However, we did observe a significant correlation between the reductions in DA D2 BP (activation of DA D2 neurotransmission) and the individual Fagerström scale scores $(r=-0.84, p<0.02)$.

The lower regional BP during the low nicotine smoking condition (compared to baseline studies in nonsmokers) and the increases in $\mu$-opioid receptor BP obtained from denicotinized to nicotine smoking conditions were both unexpected, and may indicate a substantial endogenous opioid tone during the low nicotine smoking condition. Therefore, we also examined whether changes in VAS scores from before to after smoking denicotinized cigarettes would be related to the subsequent increases in regional BP after smoking the nicotine-containing cigarettes. Significant negative correlations were obtained between the change in VAS 'nervous' $(r=-0.86, p<0.03)$ and 'relaxed' scores $(r=-0.83, p<0.05)$ during the denicotinized condition and the subsequent increases in thalamic $\mu$-opioid BP during the nicotine smoking condition. Similar effects were obtained for the change in VAS craving scores during the denicotinized condition and the increases in $\mathrm{BP}$ after nicotine smoking in the amygdala $(r=-0.84, p<0.04)$.

Correlations between plasma levels and changes in receptor $B P$. The reductions in DA D2 $\mathrm{BP}$ in the ventral basal ganglia, indicative of DA release and activation of DA D2 receptors during nicotine smoking, were correlated with peak plasma nicotine levels $(r=-0.74, p<0.05)$. Conversely, the increases in ventral basal ganglia $\mu$-opioid receptor BP during average nicotine smoking were the ones 
positively correlated with peak plasma levels of nicotine $(r=0.83, p<0.04)$.

\section{DISCUSSION}

This pilot study was undertaken to examine the feasibility to quantify changes in DA and endogenous opioid neurotransmission during smoking in humans with molecular imaging techniques. Both these neurotransmitter systems have been centrally implicated in the neurobiological effects of nicotine (Tanda and Di Chiara, 1998; Walters et al, 2005) as well as a number of other substances of abuse. Furthermore, direct interactions between opioid and DA neurotransmission have been described, whereby nicotineinduced DA release in the nucleus accumbens is dependent on the activation of $\mu$-opioid receptors in ventral tegmental area cell bodies (Tanda and Di Chiara, 1998). Conversely, at the level of the basal ganglia, $\mu$-opioid receptors reduce the activity of DA-activated striatal output neurons (Steiner and Gerfen, 1998). Chronic activation of DA D2 neurotransmission has also been shown to reduce basal ganglia opioid peptide mRNA content and increase the concentration of $\mu$ opioid receptors and mRNA in basal ganglia and cortical regions whether owing to agonist administration, blockade of DA reuptake (Hurd and Herkenham, 1993; Angulo and McEwen, 1994; Zubieta et al, 1996; Unterwald, 2001), or genetic variants associated with poorer DA metabolism (Zubieta et al, 2003). Beyond the specific effects of nicotine, the results presented demonstrate the feasibility of studying the function of two neurotransmitter systems, the dopaminergic and opioid, directly and noninvasively in humans. These neurotransmitters and their interactions, as noted above, have been implicated in the pathophysiology of various substance use disorders, but also in the effects of natural rewards (eg food, sex) (Berridge and Robinson, 2003; Nestler, 2005). They are implicated in the regulation of emotion and attachment (Zubieta et al, 2003; Moles et al, 2004), and in the regulation of the responses of the organism to environmental events, both negative (stressors) (Zubieta et al, 2001, 2003; Pruessner et al, 2004) and positive (eg placebo effects when there is expectation of recovery) (de la Fuente-Fernandez et al, 2001; Benedetti et al, 2005; Zubieta et al, 2005). This methodology therefore has the potential to aid in the investigation of individual differences in these processes, and their disruption in pathological states.

Smoking an average nicotine content cigarette was associated with the activation of both DA D2 and $\mu$-opioid release, as evidenced by reductions in the in vivo availability of DA D2 and $\mu$-opioid receptors from denicotinized to average nicotine smoking conditions. For the DA system, these effects took place in the ventral striatum (ventral putamen), consistent with the results of Brody et al (2002). The magnitude of nicotine-induced activation of ventral basal ganglia DA D2 neurotransmission was further correlated with Fagerström scores of nicotine dependence. Cortical effects could not be observed with $\left[{ }^{11} \mathrm{C}\right]$ raclopride owing to the negligible specific binding of this radiotracer in extrastriatal areas. For the $\mu$-opioid system, evidence of activation of release was obtained in the rostral and dorsal anterior cingulate. These are brain areas implicated in the anticipation of reward (Kilts et al, 2001), and in distinguishing between potentially rewarding and nonrewarding outcomes (Knutson et al, 2003), but also affective regulation and antinociceptive effects (Rainville et al, 1997; Zubieta et al, 2001).

Two sets of unexpected results were obtained in these studies. Whereas the chronic administration of nicotine has been associated with an upregulation of $\mu$-opioid receptor mRNA and protein concentrations in rodents (Wewers et al, 1999; Walters et al, 2005), we observed lower regional in vivo availability of these receptors in smokers during the denicotinized smoking condition, as compared to baseline data from nonsmoker controls. These reductions were localized in the anterior cingulate, thalamus, ventral basal ganglia, and amygdala. Furthermore, most of these regions (with the exception of the anterior cingulate) demonstrated significant increases in $\mu$-opioid receptor BP from smoking denicotinized to average nicotine content cigarettes, reflecting a reduction in endogenous opioid tone. Thalamic increases in BP were associated with increases in 'alertness' scores.

Reductions in the BP measure between conditions are interpreted as an index of neurotransmitter release and dopaminergic and opioid system activation. These changes may represent various processes associated with receptor activation by the neurotransmitter, such as competition between radiotracer and endogenous ligand, changes in the conformational state of the receptor after activation, or even receptor internalization and trafficking (Laruelle, 2000; Narendran et al, 2004). However, all these processes are related to the activation of endogenous neurotransmission, and are referred to as reflecting 'activation' of neurotransmission and the receptor sites. In the case of nicotine-induced increases in BP, this 'deactivation' of neurotransmission would require that considerable endogenous opioid tone would be present in the denicotinized smoking condition. Although this was not directly investigated in the present report, substantial baseline endogenous opioid tone has been described in the rodent basal ganglia (Zangen et al, 1999) and amygdala (Kraus et al, 1996; Gestreau and Besson, 2000). Consistent with the presence of this tone in human subjects, the opioid receptor antagonist naloxone increased the activity of a number of cortical (eg anterior cingulate, prefrontal and insular, entorhinal and parahippocampal cortices) and subcortical (eg basal ganglia, hippocampus) regions in a recent fMRI study (Borras et al, 2004).

The sample sizes reported here are small, impacting on the capacity to find significant effects. In the case of the significant correlations reported (eg Fagerström scores and the DA D2 system activation, alert VAS scores, and $\mu$-opioid system responses), these would not have survived correction for multiple comparisons, and should be interpreted as preliminary. The relationship between changes in BP after nicotine administration and its aversive or reinforcing effects therefore remains to be investigated in larger samples.

Exposure to both nicotine and environmental cues associated with nicotine exposure has been shown to induce activation of $\mu$-opioid receptor-mediated neurotransmission in rodents (Walters et al, 2005). It is therefore possible that smoking the denicotinized cigarette after overnight 
abstinence would have induced an increase activity of this neurotransmitter system by effects not related to those of nicotine itself (ie cognitive-emotional responses to smoking), resulting in both lower $\mathrm{BP}$ during low nicotine smoking and an increase in BP during the second experimental period (average nicotine content cigarettes). This possibility also seems supported by the findings of significant correlations between amygdala and thalamus BP increases from low to average nicotine conditions, and the changes in 'craving', 'nervous', and 'relaxed' scores from before to after smoking the denicotinized cigarettes. If an increased endogenous opioid tone would indeed be induced by smoking denicotinized cigarettes, this would point to non-nicotine elements of smoking as an important modulator of neurotransmitter systems (eg opioid) related to smoking behavior and nicotine effects (Walters et al, 2005), in a manner akin to that reported for placebo-induced activation of endogenous opioid neurotransmission (Zubieta et al, 2005).

In view of the results obtained in these preliminary studies, it would be important to further examine the effects of smoking on DA D2 and $\mu$-opioid neurotransmission and their behavioral correlates while taking into account nonnicotine elements of smoking. Nicotine-associated sensory cues have been shown to elicit an increase in the expression of the immediate-early gene c-fos in prefrontal cortical and limbic regions of rodents (Schroeder et al, 2001), increases in the metabolic demands of the anterior cingulate cortex in humans (Brody et al, 2002), as well as in $\mu$-opioid receptormediated increases in the transcription factor CREB that parallel the effects of drug itself (Walters et al, 2005). Nicotine-associated effects (enhancement of DA D2 neurotransmission in the ventral basal ganglia, and of $\mu$-opioid neurotransmission in the anterior cingulate cortex), as well as indirect indications of changes in the in vivo availability of $\mu$-opioid receptors when smoking denicotinized cigarettes are reported here. Future studies will need to incorporate both baseline scans (no intervention) as well as control for non-nicotine effects of smoking to fully elucidate the neurobiological effects of cigarette smoking in humans.

\section{ACKNOWLEDGEMENTS}

This work was supported in part by the Department of Pharmacology Psychopharmacology Research Fund C361024 and by the National Institute of Health Grants R01 DA 016423 and R01 AT 001415 to JKZ. We thank the members of the University of Michigan PET Facility for making this research possible.

\section{REFERENCES}

Aceto MD, Scates SM, Ji Z, Bowman ER (1993). Nicotine's opioid and anti-opioid interactions: proposed role in smoking behavior. Eur J Pharmacol 248: 333-335.

Angulo JA, McEwen BS (1994). Molecular aspects of neuropeptide regulation and function in the corpus striatum and nucleus accumbens. Brain Res Brain Res Rev 19: 1-28.

Benedetti F, Mayberg HS, Wager TD, Stohler CS, Zubieta JK (2005). Neurobiological mechanisms of the placebo effect. J Neurosci 25: 10390-10402.
Berridge KC, Robinson TE (2003). Parsing reward. Trends Neurosci 26: 507-513.

Borras MC, Becerra L, Ploghaus A, Gostic JM, DaSilva A, Gonzalez $\mathrm{RG}$ et al (2004). fMRI measurement of CNS responses to naloxone infusion and subsequent mild noxious thermal stimuli in healthy volunteers. J Neurophysiol 91: 2723-2733.

Brody AL, Mandelkern MA, London ED, Childress AR, Lee GS, Bota RG et al (2002). Brain metabolic changes during cigarette craving. Arch Gen Psychiatry 59: 1162-1172.

Carboni E, Bortone L, Giua C, Di Chiara G (2000a). Dissociation of physical abstinence signs from changes in extracellular dopamine in the nucleus accumbens and in the prefrontal cortex of nicotine dependent rats. Drug Alcohol Depend 58: 93-102.

Carboni E, Silvagni A, Rolando MT, Di Chiara G (2000b). Stimulation of in vivo dopamine transmission in the bed nucleus of stria terminalis by reinforcing drugs. J Neurosci 20: RC102.

Davenport KE, Houdi AA, Van Loon GR (1990). Nicotine protects against mu-opioid receptor antagonism by beta-funaltrexamine: evidence for nicotine-induced release of endogenous opioids in brain. Neurosci Lett 113: 40-46.

de la Fuente-Fernandez R, Ruth TJ, Sossi V, Schulzer M, Calne DB, Stoessl AJ (2001). Expectation and dopamine release: mechanism of the placebo effect in Parkinson's disease. Science 293: $1164-1166$.

Di Chiara G (2000). Role of dopamine in the behavioural actions of nicotine related to addiction. Eur J Pharmacol 393: 295-314.

Domino EF, Ni L (2002). Clinical phenotyping strategies in selection of tobacco smokers for future genotyping studies. Prog Neuropsychopharmacol Biol Psychiatry 26: 1071-1078.

Eiden LE, Giraud P, Dave JR, Hotchkiss AJ, Affolter HU (1984). Nicotinic receptor stimulation activates enkephalin release and biosynthesis in adrenal chromaffin cells. Nature 312: 661-663.

First M, Spitzer R, Gibbon M, Williams J (1995). Structured Clinical Interview for DSM-IV Axis I Disorders. Biometrics Research Department, New York Psychiatric Institute: New York.

Friston KJ, Worsley KJ, Frackowiak RSJ, Mazziotta JC, Evans AC (1994). Assessing the significance of focal activations using their spatial extent. Hum Brain Mapp 1: 210-220.

Gestreau C, Besson J (2000). Is there tonic activity in the endogenous opioid systems? A c-Fos study in the rat central nervous system after intravenous injection of naloxone or naloxone-methiodide [in process citation]. J Comp Neurol 427: 285-301.

Gorelick DA, Rose J, Jarvik ME (1988). Effect of naloxone on cigarette smoking. J Subst Abuse 1: 153-159.

Heatherton TF, Kozlowski LT, Frecker RC, Fagerstrom KO (1991). The Fagerstrom test for nicotine dependence: a revision of the Fagerstrom tolerance questionnaire. $\mathrm{Br} \mathrm{J}$ Addict 86: 1119-1127.

Houdi AA, Pierzchala K, Marson L, Palkovits M, Van Loon GR (1991). Nicotine-induced alteration in Tyr-Gly-Gly and Metenkephalin in discrete brain nuclei reflects altered enkephalin neuron activity. Peptides 12: 161-166.

Hurd YL, Herkenham M (1993). Molecular alterations in the neostriatum of human cocaine addicts. Synapse 13: 357-369.

Jewett DM (2001). A simple synthesis of $\left[{ }^{11} \mathrm{C}\right]$ carfentanil using an extraction disk instead of HPLC. Nucl Med Biol 28: 733-734.

Karras A, Kane JM (1980). Naloxone reduces cigarette smoking. Life Sci 27: 1541-1545.

Kilts CD, Schweitzer JB, Quinn CK, Gross RE, Faber TL, Muhammad F et al (2001). Neural activity related to drug craving in cocaine addiction. Arch Gen Psychiatry 58: 334-341.

Knutson B, Fong GW, Bennett SM, Adams CM, Hommer D (2003). A region of mesial prefrontal cortex tracks monetarily rewarding outcomes: characterization with rapid event-related fMRI. Neuroimage 18: 263-272.

Koob GF, Le Moal M (2001). Drug addiction, dysregulation of reward, and allostasis. Neuropsychopharmacology 24: 97-129. 
Kraus M, Piper J, Kornetsky C (1996). Naloxone alters the local metabolic rate for glucose in discrete bran regions associated with opiate withdrawal. Brain Res 724: 33-40.

Laruelle M (2000). Imaging synaptic neurotransmission with in vivo binding competition techniques: a critical review. J Cereb Blood Flow Metab 20: 423-451.

Logan J, Fowler JS, Volkow ND, Wang GJ, Ding YS, Alexoff DL (1996). Distribution volume ratios without blood sampling from graphical analysis of PET data. J Cereb Blood Flow Metab 16: 834-840.

Malin DH, Lake JR, Carter VA, Cunningham JS, Wilson OB (1993). Naloxone precipitates nicotine abstinence syndrome in the rat. Psychopharmacology (Berl) 112: 339-342.

Minoshima S, Koeppe RA, Mintun MA, Berger KL, Taylor SF, Frey KA et al (1993). Automated detection of the intercommissural line for stereotactic localization of functional brain images. J Nucl Med 34: 322-329.

Moles A, Kieffer BL, D’Amato FR (2004). Deficit in attachment behavior in mice lacking the mu-opioid receptor gene. Science 304: 1983-1986.

Narendran R, Hwang DR, Slifstein M, Talbot PS, Erritzoe D, Huang $\mathrm{Y}$ et al (2004). In vivo vulnerability to competition by endogenous dopamine: comparison of the $\mathrm{D} 2$ receptor agonist radiotracer $(-)-N-\left[{ }^{11} \mathrm{C}\right]$ propyl-norapomorphine $\left(\left[{ }^{11} \mathrm{C}\right] \mathrm{NPA}\right)$ with the D2 receptor antagonist radiotracer $\left[{ }^{11} \mathrm{C}\right]$-raclopride. Synapse 52: 188-208.

Nemeth-Coslett R, Griffiths RR (1986). Naloxone does not affect cigarette smoking. Psychopharmacology (Berl) 89: 261-264.

Nestler EJ (2005). Is there a common molecular pathway for addiction? Nat Neurosci 8: 1445-1449.

Pomerleau OF (1998). Endogenous opioids and smoking: a review of progress and problems. Psychoneuroendocrinology 23: 115-130.

Pruessner JC, Champagne F, Meaney MJ, Dagher A (2004). Dopamine release in response to a psychological stress in humans and its relationship to early life maternal care: a positron emission tomography study using $\left[{ }^{11} \mathrm{C}\right]$ raclopride. J Neurosci 24: 2825-2831.

Rainville P, Duncan G, Price D, Carrier B, Bushnell M (1997). Pain affect encoded in human anterior cingulate but not somatosensory cortex. Science 277: 968-971.

Schroeder BE, Binzak JM, Kelley AE (2001). A common profile of prefrontal cortical activation following exposure to nicotineor chocolate-associated contextual cues. Neuroscience 105: 535-545.
Steiner H, Gerfen CR (1998). Role of dynorphin and enkephalin in the regulation of striatal output pathways and behavior. Exp Brain Res 123: 60-76.

Sutherland G, Stapleton JA, Russell MA, Feyerabend C (1995). Naltrexone, smoking behaviour and cigarette withdrawal. Psychopharmacology (Berl) 120: 418-425.

Tanda G, Di Chiara G (1998). A dopamine-mul opioid link in the rat ventral tegmentum shared by palatable food (Fonzies) and non-psychostimulant drugs of abuse. Eur J Neurosci 10: 1179-1187.

Unterwald EM (2001). Regulation of opioid receptors by cocaine. Ann N Y Acad Sci 937: 74-92.

Volkow ND, Fowler JS, Wang GJ, Swanson JM (2004). Dopamine in drug abuse and addiction: results from imaging studies and treatment implications. Mol Psychiatry 9: 557-569.

Walters CL, Cleck JN, Kuo YC, Blendy JA (2005). Mu-opioid receptor and CREB activation are required for nicotine reward. Neuron 46: 933-943.

Wewers ME, Dhatt RK, Snively TA, Tejwani GA (1999). The effect of chronic administration of nicotine on antinociception, opioid receptor binding and met-enkelphalin levels in rats. Brain Res 822: $107-113$.

Worsley K, Evans A, Marrett S, Neelin P (1992). A threedimensional statistical analysis for CBF activation studies in human brain. J Cereb Blood Flow Metab 12: 900-918.

Zald DH, Boileau I, El-Dearedy W, Gunn R, McGlone F, Dichter GS et al (2004). Dopamine transmission in the human striatum during monetary reward tasks. J Neurosci 24: 4105-4112.

Zangen A, Nakash R, Yadid G (1999). Serotonin-mediated increases in the extracellular levels of beta-endorphin in the arcuate nucleus and nucleus accumbens: a microdialysis study. J Neurochem 73: 2569-2574.

Zubieta J, Smith Y, Bueller J, Xu Y, Kilbourn M, Meyer C et al (2001). Regional mu opioid receptor regulation of sensory and affective dimensions of pain. Science 293: 311-315.

Zubieta JK, Bueller JA, Jackson LR, Scott DJ, Xu Y, Koeppe RA et al (2005). Placebo effects mediated by endogenous opioid activity on mu-opioid receptors. J Neurosci 25: 7754-7762.

Zubieta JK, Gorelick DA, Stauffer R, Ravert HT, Dannals RF, Frost JJ (1996). Increased mu opioid receptor binding detected by PET in cocaine-dependent men is associated with cocaine craving. Nat Med 2: 1225-1229.

Zubieta JK, Heitzeg MM, Smith YR, Bueller JA, Xu K, Xu Y et al (2003). COMT val158met genotype affects mu-opioid neurotransmitter responses to a pain stressor. Science 299: 1240-1243. 